\title{
вмJ Global Health Governing multisectoral action for health in low-income and middle- income countries: an agenda for the way forward
}

\author{
Kumanan Rasanathan, ${ }^{1}$ Vincent Atkins, ${ }^{2}$ Charles Mwansambo, ${ }^{3}$ Agnès Soucat, ${ }^{4}$ \\ Sara Bennett ${ }^{5}$
}

To cite: Rasanathan $\mathrm{K}$, Atkins $\mathrm{V}$, Mwansambo C, et al. Governing multisectoral action for health in low-income and middle-income countries: an agenda for the way forward. BMJ Glob Health 2018;3:e000890. doi:10.1136/ bmjgh-2018-000890

Handling editor Seye Abimbola

Received 10 April 2018

Revised 23 July 2018

Accepted 17 August 2018
Check for updates

(c) Author(s) (or their employer(s)) 2018. Re-use permitted under CC BY-NC. No commercial re-use. See rights and permissions. Published by BMJ.

${ }^{1}$ Health Section, UNICEF, New York City, New York, USA ${ }^{2}$ Caribbean Community, Bridgetown, Barbados

${ }^{3}$ Ministry of Health, Lilongwex, Malawi

${ }^{4}$ World Health Organization, Geneva, Switzerland

${ }^{5}$ Department of International Health, Johns Hopkins Bloomberg School of Public Health, Baltimore, Maryland, USA

Correspondence to Dr Kumanan Rasanathan; kumananr@yahoo.com

\section{ABSTRACT}

Drawing on experiences reviewed in the accompanying supplement and other literature, we present an agenda for the way forward for policy-makers, managers, civil society and development partners to govern multisectoral action for health in low-income and middle-income countries and consider how such an agenda might be realised. We propose the following key strategies: understand the key actors and political ecosystem, including type of multisectoral action required and mapping incentives, interests and hierarchies; frame the issue in the most strategic manner; define clear roles with specific sets of interventions according to sector; use existing structures unless there is a compelling reason not to do so; pay explicit attention to the roles of non-state sectors; address conflicts of interest and manage tradeoffs; distribute leadership; develop financing and monitoring systems to encourage collaboration; strengthen implementation processes and capacity; and support mutual learning and implementation research. To support countries to strengthen governance for multisectoral action, the global community can assist by further developing technical tools and convening peer learning by policy-makers (particularly from beyond the health sector), supporting knowledge management and sharing of experiences in multisectoral action beyond health, developing an agenda for and execution of implementation research and, finally, driving multilateral and bilateral development partners to transcend their own silos and work in a more multisectoral manner.

As Bennett et al describe in the introductory paper to this supplement, the evidence is clear on the need for multisectoral action to achieve improved health outcomes (Bennett et $a$ l).$^{1-7}$ It is also clear that the health goal and targets adopted by all countries in the Sustainable Development Goals (SDGs) in 2015 will not be achieved without working in an integrated manner across functional sectors (such as health, education, finance, trade and social welfare) ${ }^{8}{ }^{9}$ The papers in this supplement have highlighted the importance of governance, with a focus on low-income and middle-income countries, to
Summary box

- Governing multisectoral action for health is essential to achieve the Sustainable Development Goals, and the accompanying supplement to this paper provides evidence to inform key strategies to take this forward in low-income and middle-income countries.

- Key strategies include understanding the political ecosystem, managing relationships and conflicts between stakeholders, distributing leadership, providing incentives for institutions and individuals to collaborate and undertaking implementation research to improve the evidence base.

- The global community can contribute through development of tools, bringing together policy-makers to share experiences, supporting research and improving their own practice in working multisectorally.

support such multisectoral action. Drawing on these and other experiences, here we present an agenda for the way forward to govern multisectoral action for health in low-income and middle-income countries and consider how such an agenda might be realised.

As noted by Glandon et al, ${ }^{10}$ the evidence for what works to enable multisectoral action for health in practice is not robust-even more so for addressing governance challenges. The agenda in this paper therefore builds on the papers in this supplement and other existing literature as well as discussions during a workshop on the theme of Governing Multisectoral Action for Health for Low-Income and Middle-Income Countries hosted by The Rockefeller Foundation's Bellagio Center in June 2016, which was the genesis of this supplement. The agenda also builds on our experience working in this field in low-income and middle-income countries as policy-makers, researchers and 
Box 1 Key strategies to govern multisectoral action for health in low-income and middle-income countries

1. Understand the key actors and political ecosystem, including type of multisectoral action required and mapping incentives, interests and hierarchies.

2. Frame the issue in the most strategic manner.

3. Define clear roles with specific sets of interventions according to sector.

4. Use existing structures unless there is a compelling reason not to do so.

5. Pay explicit attention to the roles of non-state sectors.

6. Address conflicts of interest and manage tradeoffs.

7. Distribute leadership.

8. Develop financing and monitoring systems to encourage collaboration.

9. Strengthen implementation processes and capacity.

10. Support mutual learning and implementation research.

development partners. Some of these discussions have been previously synthesised elsewhere,${ }^{11}$ and this paper also builds on these ideas.

\section{KEY STRATEGIES TO GOVERN MULTISECTORAL ACTION FOR HEALTH IN LOW-INCOME AND MIDDLE-INCOME COUNTRIES}

The premise in advocating for a greater focus on governance of multisectoral action rests on the complexity of bridging the efforts of actors within institutions (with diverse ways of working) with different ideas (and worldviews and languages) and different interests to work towards a common goal for which they are not necessarily accountable. The health sector has often struggled to address the interests of other sectors or make the case for why other sectors should focus on health gain-but it has also struggled to contribute to governance mechanisms and processes by which multisectoral action for health can be successfully implemented. ${ }^{12}$

We propose a set of key strategies for the governance of multisectoral action in box 1 . These strategies are not intended to be a step-by-step guide or systematic framework for governing multisectoral action. For some types of multisectoral action where there are clear conflicts between sectors (such as controlling alcohol or tobacco) issues of power, interests and incentives may be key. For other types of multisectoral action (such as addressing child poverty), questions around coordination and developing implementation processes and capacity may take priority. Other papers in this supplement consider potential frameworks for multisectoral action (Emerson, ). ${ }^{13}$ Our intention here in highlighting these strategies is to distil areas of work that deserve consideration for those embarking on governing multisectoral action for health, as they construct the specific strategies and plans for implementation. Below, we discuss each of these strategies in turn.
Understand the key actors and political ecosystem, including type of multisectoral action required and mapping incentives, interests and hierarchies

The papers in this supplement again emphasise that the most important barriers to multisectoral action are political rather than technical. This observation is not a new-but translating this understanding into practical measures to overcome political barriers has proved difficult. Fortunately, development agencies have produced an increasing number of tools and approaches that can provide a guide to identifying and mapping key actors, unpacking the power and authority that they wield and sketching the political ecosystem they inhabit, including respective histories, institutional capabilities and accountabilities. ${ }^{14-16}$ In our experience, it is relatively rare that national or global actors systematically apply a political economy lens to multisectoral action, and this could be immensely helpful.

The type of actors involved in multisectoral action varies considerably according to the issue being considered, ${ }^{11}$ so there is no single blueprint for success. The governance for loosely coordinating a range of actions within single sectors differs markedly to that required for addressing 'wicked' problems affecting all of society. ${ }^{17}{ }^{18}$ Careful analysis is required in each case, including mapping the interests (including incentives), ideas and institutions (including relationships and hierarchies of the key actors) required for action. Doing so helps to understand different sectors and actors' approach to the problem at hand. For example, hierarchies such as the relative power of the Ministry of Health compared with other sectors are most often tacit rather than explicit, but their recognition is key to understanding the role the Ministry of Health can play in leading and convening multisectoral action, or considering which sector is instead best placed to lead. Mapping of interests and relationships is also important for considering which systems are required to address the current problem. Kanchanachitra et $a l^{19}$ in this supplement undertake this type of mapping retrospectively with respect to implementing policy on asbestos in Thailand-if this type of mapping had occurred earlier in this case, there may have been a clearer understanding of the barriers to implementing policy.

\section{Frame the issue in the most strategic manner}

The way in which an issue is framed, for example, whether it emphasises benefits in terms of development, equity, economic or health outcomes, has an essential impact on to whom it appears as relevant or a priority. The concept of 'health imperialism' refers to the behaviour of the health sector in assuming that health interests predominate and that if other sectors understand their potential contribution to improving health through their actions, they should automatically be motivated to act in such a way to facilitate this health improvement. ${ }^{20}$ The consequence of such thinking is the premise that education and awareness are sufficient to motivate other sectors' contribution to health. As non-health sectors usually do not have accountabilities for health outcomes, such an approach is often 
unsuccessful. Rather, it is important to frame issues in terms that are central to the sector whose participation is desired. It is also helpful to link issues with high-level political agendas as this may also induce buy-in for multisectoral action, as seen in the accompanying paper in this supplement by Zaidi $e t a l^{21}$ in the case of nutrition in Pakistan. The integration of the SDGs into national development plans may provide an opportunity to link health to other development priorities, but most important is to ensure that attempts at multisectoral action link to compelling national narratives. In summary, advocates for multisectoral action for health need to take a more integrated view of development considering the broader benefits of actions that improve health.

\section{Define clear roles with specific sets of interventions according to sector}

If buy-in from other sectors can be achieved to contribute to health, it is still important to clearly define the roles of each sector, with a specific set of interventions that each sector will implement and indicators that can be measured with existing data. Doing so also allows budgeting for each sector's role and inclusion of these activities in sectoral plans and policies. The Chile Crece Contigo multisectoral programme for early child development, where each sector involved had an explicit set of activities with distinct indicators for their contribution, is a good example of how this can be implemented and how it can facilitate success in the goals of multisectoral action. ${ }^{22-24}$ Without this specificity of role, there can be a lack of accountability for multisectoral action by each sector in terms of their contribution.

\section{Use existing structures unless there is a compelling reason not to do so}

The history of multisectoral action for health is littered with 'interministerial committees' and 'multisectoral working groups', for example, the Coordinating Office for Control of Trypanosomiasis in Uganda highlighted in this supplement. ${ }^{25}$ Yet, multisectoral efforts are much more likely to achieve their aims if institutionalised in existing structures, as seen in the comparative trajectories of early child development and nutrition multisectoral efforts in Pakistan described by Zaidi et al in this issue. Similarly, leadership from existing networks or mechanisms, rather than novel groups, is more likely to result in sustained action. There is significant risk in having action fuelled by a single personality or group, especially when an issue or its challenges are ongoing. New committees or structures that are not seen as part of core mandates of sectors can be helpful in initiating action but are rarely successful in the long term. This is not to say that new structures will not sometimes be necessary, especially in contexts where there is limited experience of multisectoral action for health. But the barrier to constructing new structures and entities should be high and careful consideration should be given to how such new entities will successfully operate with existing institutions, considering the incentives for actors to engage with them and their political and financial sustainability from the outset.

\section{Pay explicit attention to the roles of non-state sectors}

Efforts at multisectoral action for health often focus on interactions between functional or thematic sectors. But attention must also be paid to interactions between stakeholder sectors and in particular to the roles and responsibilities of non-state sectors, such as civil society and the private sector. The same warnings against instrumentalising' the interests of other functional sectors also apply in these interactions. Civil society groups can be strong advocates and contributors to multisectoral action for health, with many successful examples from low-income and middle-income countries, but overly close alignment of such groups with government is likely to undermine their legitimacy and limit their ability to press for social change ${ }^{26}$ Clarity regarding their roles is required, respecting their own interests and independence. The for-profit private sector must also not be ignored in multisectoral efforts, although such engagement can be challenging, particular where private sector interests are harmful to health, as noted further below.

\section{Address conflicts of interest and manage tradeoffs}

While much attention is paid to potential for 'win-win' investments during multisectoral action, the interests of sectors and actors often do conflict, including where health interests collide with the interests (both legitimate and illegitimate) of other sectors. This was clearly the case in Thailand in the asbestos case described by Kanchanachitra et al. Such conflicts need to be actively managed without ignoring them or a priori asserting the primacy of health interests. Not doing so risks losing engagement of sectors who feel their interests are threatened and undermining the desired multisectoral action. One approach to manage conflicts is to attempt to balance trade-offs so that sectors who perceive themselves as losing out in the short term are able to be prioritised in the future. At the same time, the health sector also needs to be careful to maintain essential health interests and not shy away from or underplay conflicts that are irreconcilable-for example, with industries that actively undermine health, such as alcohol, tobacco and weapons and their sectoral promoters.

\section{Distribute leadership}

Support from the political executive is often important for multisectoral action, in particular at the initiation stage, and there are many examples of strong leaders who have been central to successful multisectoral efforts. But it is also essential to distribute leadership and foster collaboration in governance to sustain such efforts. Dictatorial approaches are not generally the answer to sustained action. The focus should instead be on building leadership capacity across different sectors and also different levels of jurisdiction, particularly as multisectoral action can be less 
challenging at subnational levels such as municipalities and districts that may have fewer institutional silos. Champions need to be fostered across the different functional sectors from whom collaboration is required, as leaders rarely have credibility beyond their own sector. Command and control mechanisms do have utility in emergency situations-but even here, strong relationships and effective coordination are key to success.

\section{Develop financing and monitoring systems to encourage collaboration}

Financing and funding flows are key tools for governance that are underused in enabling multisectoral action. Joint financing is particularly useful to ensure collaboration between sectors in large multisectoral efforts. Devolving financing for multisectoral efforts to a single Ministry or sector to further distribute funding can empower this Ministry's convening and leadership role and sustain collaboration, as seen, for example, in the role the Ministry of Planning plays in the Chile Crece Contigo programme discussed above. Funding flows to subnational levels for implementation can also be taken advantage of to build incentives for collaboration. Performance-based financing, increasingly popular in the funding of health services, has not been employed to stimulate multisectoral collaboration to date. While this may not be appropriate in all contexts (and the evidence for performance-based financing in the health sector is mixed ${ }^{27}$ ), other methods of financial incentives should be considered. Similarly, joint monitoring systems that enable joint accountability for shared outcomes are also underused tools for governing multisectoral action, notwithstanding the data challenges of monitoring across sectors or of evaluating health impacts from action on determinants.

\section{Strengthen implementation processes and capacity}

While a key feature of many low-income and middle-income countries is their weak institutional capacity, implementation processes for multisectoral action are particularly challenging and require specific attention, especially at the beginning of multisectoral efforts. There are differing organisational and disciplinary cultures between and within sectors, creating difficulties in aligning monitoring indicators and sharing datasets. Assessing and attributing each sector's contribution is also challenging. Accountability, transparency and trust help drive multisectoral action, but can be elusive. Innovation, adaptation and flexibility are required in terms of political, financial and administrative accountability to strengthen the governance of multisectoral implementation efforts. While it is easy to urge governments to create greater capacity for multisectoral action, the magnitude of this task needs to be recognised. Organisational capacity development in many contexts is a complex, long-term task, that likely encompasses many branches of government, levels of jurisdiction and types of capacity needs.

\section{Support mutual learning and implementation research}

Given the challenges of multisectoral action for health and the gaps in evidence for what works, particularly in low-income and middle-income countries, there is a pressing need to nurture mutual learning, sharing knowledge and lessons between the diversity of stakeholders involved. Glandon et al identify some of the pressing areas where new understanding is required, but their paper also highlights the need for further development and application of conceptual frameworks and theoretical models in the analysis of multisectoral action. There is also a need to foster implementation research embedded in programme design and execution, so that course corrections can be made in a timely manner if outcomes are not as anticipated. ${ }^{28}$ Existing approaches for monitoring and evaluation are often insufficient for the demands of multisectoral action (which does not operate within a single disciplinary paradigm), so technical work to refine quantitative and qualitative methods and develop indicators is also required.

\section{What is required to support low-income and middle- income countries to take forward this agenda for governing multisectoral action for health?}

We acknowledge that taking forward the agenda we have presented above is challenging in most low-income and middle-income settings. Issues of lack of capacity, lack of resources, poor governance, corruption and weak accountability undermine many efforts to strengthen governance of multisectoral action, even in settings where the need for such action is genuinely understood as important. ${ }^{29}$

The SDGs provide an opportunity to catalyse multisectoral action in that in principle they present an integrated and indivisible agenda. ${ }^{30}$ In practice, however, sectors tend to focus on individual SDGs and constituent targets that they recognise as 'belonging' to their sectors-mirroring the process by which the SDGs were developed that was also mostly in sectoral silos. ${ }^{31}$ But as countries continue the process of translating the SDGs into national plans and strategies, it is timely to strengthen governance across sectors in a way that facilitates multisectoral action for health, given that the capacity to act multisectorally is also required for a diverse range of other key development challenges in the SDGs, including poverty reduction, climate change mitigation and adaptation and advancing gender equality.

To support multisectoral action requires investments in financing, human resources and systems for accountability, and these requirements have been articulated elsewhere. ${ }^{6}$ Specific to strengthening governance for multisectoral action, we would like to highlight four key areas to which the global community can contribute.

First, there is scope to further develop technical tools to support governance of multisectoral action, including those derived from the Health in All Policies discourse, ${ }^{20}$ but capacity building should also focus on peer learning among policy-makers. For example, the model of the Joint Learning Network which supports efforts towards universal health coverage could be emulated for work on multisectoral action. Governance for multisectoral action is highly context-specific but bringing together policy-makers from different sectors to share their experiences and understand how they have made progress has not been sufficiently 
supported, despite the obvious promise and value of efforts where this has occurred. Too much of the work on multisectoral action for health has failed to genuinely engage policy-makers from other sectors, instead being overly dominated by those in public health. So, renewed efforts to bring together stakeholders from the diverse sectors required for multisectoral action for health are warranted.

Second, and building on efforts to convene policy-makers for peer learning, knowledge management to synthesise existing literature and documentation of experiences would be helpful, for example, building on resources such as the discourse around Health in All Policies and the public administration literature (Emerson) ${ }^{32}{ }^{33}$ Much can also be learnt from the governance of multisectoral experiences that do not involve the health sector, from which there has been limited learning, for example experiences in protecting the environment. As countries intensity efforts towards achieving the SDGs, there is the opportunity to build mutual learning around the required range of multisectoral efforts. The global community can also support building capacity in national institutions to steward this knowledge management and mutual learning.

Third, a clear implementation research agenda is necessary on the governance of multisectoral action for health, to rally research and learning and to reinforce the evidence base. Global institutions can support both the development of this agenda at global level and its customisation in countries, as well as capacity in national institutions to undertake such research, including assembling and sharing case studies. The priorities identified by Glandon $e t$ al in the paper in this supplement (reproduced in table 1) provide a useful basis for the further development of this research agenda and developing specific research questions that can be supported.

Fourth and finally, multilateral and bilateral development partners should make themselves fit for purpose to support the governance of multisectoral action for health within countries by examining their own governance and transcending their own silos. This will be particularly difficult for global organisations that mostly operate explicitly within a single sector or with an exclusive relationship to single ministries, but even genuinely multisectoral organisations often find it challenging to overcome internal fragmentation. This is not to detract from the value of sectoral specialisation in increasing efficiency or to suggest that all organisations should try to work across all sectors. But as with countries, global organisations are also struggling to move from the mindset of the Millennium Development Goals to the 'integrated and indivisible' development agenda of the SDG era. Genuinely examining their own capacity to work multisectorally should be integral to this transition in global governance arrangements to support countries.

\section{CONCLUSION}

Despite the lack of systematic evidence on what works to strengthen governance for multisectoral action for health in low-income and middle-income countries, lessons from existing case studies and discourses, including those featured in this supplement, provide guidance on how to do so. The agenda we have presented above distils these

\section{Table 1 Top 10 ranked research questions on multisectoral collaboration for health (reproduced from Glandon et al)}

\section{Rank Research question}

Unweighted final score

\begin{tabular}{|c|c|c|}
\hline 1 & $\begin{array}{l}\text { Which strategies and mechanisms are effective in supporting the implementation of multisectoral } \\
\text { collaborations for health? (eg, enabling legislation, policy mandate, decentralised control, } \\
\text { accountability and incentive mechanisms, dedicated resources, training/skill development and so on) }\end{array}$ & $67.9 \%$ \\
\hline 2 & What factors are necessary for sustaining multisectoral collaborations over time? & $63.0 \%$ \\
\hline 3 & $\begin{array}{l}\text { How does the use of evidence differ across different sectors and how can we make health evidence } \\
\text { more accessible and actionable in other sectors? }\end{array}$ & $62.7 \%$ \\
\hline 3 & $\begin{array}{l}\text { What is the role of community-based partnerships and initiatives in driving multisectoral collaborations } \\
\text { for health? }\end{array}$ & $62.7 \%$ \\
\hline 5 & $\begin{array}{l}\text { What types of leadership, partnership and governance structures and processes are most effective for } \\
\text { multisectoral collaboration? }\end{array}$ & $60.0 \%$ \\
\hline 6 & $\begin{array}{l}\text { What are the key challenges to implementing multisectoral programmes and interventions to address } \\
\text { health issues (eg, food security, NCDs, HIV/AIDS)? }\end{array}$ & $59.7 \%$ \\
\hline 7 & $\begin{array}{l}\text { How do contextual factors such as institutional arrangements, governance arrangements, democratic } \\
\text { values, partnership experiences affect the success (or failure) of multisectoral collaborations? }\end{array}$ & $53.0 \%$ \\
\hline 8 & $\begin{array}{l}\text { How can we best improve the capacity of stakeholders involved in multisectoral action for health (such } \\
\text { as health advocates, or health practitioners), to engage in and also promote multisectoral initiatives? }\end{array}$ & $52.6 \%$ \\
\hline 9 & $\begin{array}{l}\text { Which study designs and methods are best suited to understanding multisectoral collaborations, their } \\
\text { governance, functioning and outcomes? }\end{array}$ & $51.8 \%$ \\
\hline 10 & How do multisectoral collaborations affect health equity and social determinants of health? & $50.9 \%$ \\
\hline 10 & How do interventions that target non-health SDGs affect health outcomes? & $50.9 \%$ \\
\hline
\end{tabular}


lessons into key strategies and the global community can do much to assist countries in taking forward these approaches. Given the importance of multisectoral action for materialising the SDG agenda, the global community can usefully apply its resources to help systematise and document evidence and case studies that test these strategies and also bring together policy-makers from health and other sectors to share their experiences in governing multisectoral action.

Acknowledgements We acknowledge Robert Beschel, Gabriel Carrasquilla, Jodi Charles, Rajib Dasgupta, Kirk Emerson, Douglas Glandon, Churnrurtai Kanchanachitra, Pete Kingsley, Don Matheson, Rees Murithi Mbabu, Michael Myers, Jeremias Paul Jr, Thulisile Radebe, James Smith, Orielle Solar, Aloysius Ssennyonjo, Matthias Wismar and Shehla Zaidi, who contributed to the Bellagio Center meeting on Governing Multisectoral Action for Health in Low-Income and Middle-Income Countries in June 2016 and shared experiences that informed this paper from Cambodia, Chile, Colombia, India, Kenya, Malawi, Pakistan, the Philippines, Thailand, Uganda, the Caribbean, the Pacific and the European region. We also acknowledge the support of The Rockefeller Foundation in the convening of the Bellagio meeting and in funding this supplement.

Contributors KR wrote the initial draft. VA, CM, AS and SB provide intellectual content to the final draft.

Funding This study was funded by Rockefeller Foundation.

Competing interests None declared.

Patient consent Not required.

Provenance and peer review Not commissioned; externally peer reviewed.

Data statement No additional data are available.

Open access This is an open access article distributed in accordance with the Creative Commons Attribution Non Commercial (CC BY-NC 4.0) license, which permits others to distribute, remix, adapt, build upon this work non-commercially, and license their derivative works on different terms, provided the original work is properly cited and the use is non-commercial. See: http://creativecommons.org/ licenses/by-nc/4.0

\section{REFERENCES}

1. Bennett S, Glandon D, Rasanathan K, et al. Governing multi sectoral action for health in low-income and middle-income countries: un packing the problem and rising to the challenge. BMJ Glob Health 2018. In press. doi: 10.1136/bmjgh-2018-000880.

2. Commission on Social Determinants of Health. Closing the gap in a generation: health equity through action on the social determinants of health: commission on social determinants of health final report. Geneva: World Health Organization, 2008.

3. McKee $M$. What can health services contribute to the reduction of inequalities in health? Scand J Public Health Suppl 2002;59:54-8.

4. McKeown T. The role of medicine: dream, mirage, or nemesis? Princeton NJ: Princeton University Press, 1979.

5. Kuruvilla S, Schweitzer J, Success Factors for Women's and Children's Health study groups. Success factors for reducing maternal and child mortality. Bull World Health Organ 2014;92:533-44.

6. Rasanathan K, Damji N, Atsbeha T, et al. Ensuring multisectoral action on the determinants of reproductive, maternal, newborn, child, and adolescent health in the post-2015 era. BMJ 2015;351:h4213.

7. Mahler H. The meaning of "Health for All by the Year 2000". Am J Public Health 2016;106:36-8.

8. Blomstedt Y, Bhutta ZA, Dahlstrand J, et al. Partnerships for child health: capitalising on links between the sustainable development goals. BMJ 2018;360:k125.

9. Countdown to 2030 Collaboration. Countdown to 2030: tracking progress towards universal coverage for reproductive, maternal, newborn, and child health. Lancet 2018;391:1538-1548.
10. Glandon D, Meghani A, Jessani N, et al. Identifying health policy and systems research priorities on multi sectoral collaboration for health in low-income and middle-income countries. BMJ Glob Health 2018. In press. doi: 10.1136/bmjgh-2018-000970.

11. Rasanathan K, Bennett S, Atkins V, et al. Governing multisectoral action for health in low- and middle-income countries. PLoS Med 2017;14:e1002285.

12. de Leeuw E. Engagement of sectors other than health in integrated health governance, policy, and action. Annu Rev Public Health 2017:38:329-49.

13. Emerson K. Collaborative governance of public health in LMICs:lessons from research in public administration. BMJ Glob Health 2018. In press. doi: 10.1136/bmjgh-2017-000381.

14. Foresti M, O'Neil T, Wild L. 2013.Making sense of the politics of delivery: our findings so far. https://www.odi.org/sites/odi.org.uk/ files/odi-assets/publications-opinion-files/8346.pdf (accessed $18 \mathrm{Jul}$ 2018).

15. Rocha Menochal A, Cassidy M, Swift S. Thinking and working politically through applied political economy analysis: a guide for practitioners. Washington: D.C:USAID 2018, 2018.

16. Fritz V, Levy B, Ort R, eds. Problem-driven political economy analysis. Washington, D.C: World Bank, 2014.

17. Signal LN, Walton MD, Ni Mhurchu C, et al. Tackling 'wicked' health promotion problems: a New Zealand case study. Health Promot Int 2013;28:84-94.

18. Walls HL. Wicked problems and a wicked' solution. Global Health 2018;14:34

19. Kanchanachitra C, Tangcharoensathien V, Patcharanarumol W, et al. Multi sectoral governance for health:challenges in implementing a total banon chrysotile asbestos in Thailand. BMJ Glob Health 2018. In press. doi: 10.1136/bmjgh-2017-000383.

20. Kickbusch I. Health in all policies: the evolution of the concept of horizontal health governance. Implementing Health in All Policies: Adelaide 2010. Adelaide: Department of Health, Government of South Australia, 2010:11-23.

21. Zaidi S, Bhutta Z, Hussain SS, et al. Multi sector governance for nutrition and early childhood development:overlapping agendas and differing progress in Pakistan. BMJ Glob Health 2018. In press. doi: 10.1136/bmjgh-2017-000678.

22. Vega J. Steps toward the health equity agenda in Chile. Background paper prepared prepared for the World Conference on Social Determinants of Health. Geneva: WHO, 2011.

23. Richter LM, Daelmans B, et al. Paper 3 working group and the lancet early childhood development series steering committee. Investing in the foundation of sustainable development: pathways to scale up for early childhood development. Lancet 2017;389:103-18.

24. de Andrade LO, Pellegrini Filho A, Solar O, et al. Social determinants of health, universal health coverage, and sustainable development: case studies from Latin American countries. Lancet 2015;385:1343-51

25. Smith J, Taylor EM, Kingsley P. One World-One Health and neglected zoonotic disease: elimination, emergence and emergency in Uganda. Soc Sci Med 2015:129:12-19.

26. Banks N, Hulme D, Edwards M. NGOs, states, and donors revisited: still too close for comfortStates, and Donors Revisited: Still Too Close for Comfort? World Dev 2015;66:707-18.

27. Paul E, Albert L, Bisala BN, et al. Performance-based financing in low-income and middle-income countries: isn't it time for a rethink? BMJ Glob Health 2018;3:e000664.

28. Ghaffar A, Langlois EV, Rasanathan $\mathrm{K}$, et al. Strengthening health systems through embedded research. Bull World Health Organ 2017;95:87.

29. Tangcharoensathien V, Srisookwatana O, Pinprateep P. Multisectoral actions for health: challenges and opportunities in complex policy environments. Int J Health Policy Manag 2017;6:359-63.

30. United Nations General Assembly. Transforming our world: the 2030 agenda for sustainable development. New York: United Nations, 2015.

31. Brolan CE, Hill PS. Universal Health Coverage's evolving location in the post-2015 development agenda: Key informant perspectives within multilateral and related agencies during the first phase of post-2015 negotiations. Health Policy Plan 2016;31:514-26.

32. Emerson K, Nabatchi T. Collaborative governance regimes. Washington, D.C: Georgetown University Press, 2015.

33. Carey G, Friel S. Understanding the role of public administration in implementing action on the social determinants of health and health inequities. Int J Health Policy Manag 2015;4:795-8. 